\title{
REVIEW: INDONESIA'S DIVERSITY REVISITED
}

\author{
J. D. Legge
}

Of all nation states emerging from colonial status after the end of World War II Indonesia has always appeared to observers to be especially a tour de force, if not an artifact of colonial rule. Its geographical spread, archipelagic character, ethnic complexity, and economic diversity hardly made it a natural candidate for independent nationhood; and indeed this seems to be part of its own self-perception. Its national motto reflects a sense almost of proud surprise that it should exist, and there have been enough threats to its unity since independence-the insurgency of Darul Islam, the development of barter trade by some regions in the 1950s, the revolts of the late 1950s-for the question of unity to remain a basic goal of policy. In the early years of independence much attention was given to the idea of local autonomy as a means of satisfying regional aspirations and meeting what were seen as the major regional grievances. From the late 1960s, the Government has hoped that economic development might reduce separatist tendencies. The elements of an integrated polity, and what constitutes progress towards integration, however, are not easy to determine. Is integration indeed a matter of fact, or of local perceptions, or of external perceptions.

For Christine Drake it seems to be a matter of fact, though admittedly complex and difficult to pin down. Integration, she says at the end of the work under review "is a vast, multifaceted, and enormously complicated concept" (p. 256), ${ }^{2}$ and the aim of her book is to give empirical substance to the concept and to apply it to Indonesia. It is not entirely clear whether it is intended to be a book about integration using Indonesia as a spectacularly difficult case, or a book about Indonesia focusing on the problem of its diversity. The opening sentence-"what is it that holds a nation together?"-suggests the former, as does its method. Drake adopts a statistical approach, identifying a variety of indices of integration and considering their spatial distribution across the archipelago. It is, however, a detailed empirical rather than a theoretical study. There are echoes of

\footnotetext{
${ }^{1}$ Christine Drake, National Integration in Indonesia: Patterns and Policies (Honolulu: University of Hawaii Press, 1989).

${ }^{2}$ Throughout this review page numbers in parentheses refer to National Integration in Indonesia.
} 
Deutsch's study of nationalism in the way the elements of the problem are sorted out, ${ }^{3}$ but there is no systematic or overarching model arising from or disciplining the evidence. Perhaps one could best see the study as an example of method. As such it is a highly stimulating work, full of suggestive detail.

The inquiry is set up at the beginning in fairly abstract terms. Four dimensions of integration are identified, the historical dimension, socio-cultural dimension, interaction dimension, and economic dimension; and within each there are a large number of specific characteristics which can be sorted out and, up to a point, measured. These can then be analyzed in terms of their spatial patterns across the Republic so as to give a sense of the integrative and disintegrative elements in the total picture.

The historical dimension is different from the others in that it doesn't have specific characteristics (except ones that overlap with one of the other three dimensions) to be analyzed in terms of spatial patterns. Drake therefore proceeds to concentrate on the socio-cultural, interaction, and economic dimensions. The socio-cultural dimension comprises such variables as the extent and pervasiveness of a national language as against the continued existence, and in places the dominance, of regional languages, the size and homogeneity of particular cultures, the degree of contact between them, ethnic differences, religious variety, the extent of education and the varying levels of literacy across the country, the role and degree of acceptability of national symbols, the spread of national organizations-cooperatives and scouting are selected here-the presence of culturally distinct minorities. Also included are access to a variety of amenities-radio, television and film, newspapers and magazines, hospital facilities. The degree of urbanization is also examined as bearing on the integration of the nation as a whole.

By the "interaction dimension" is meant interregional links achieved through transport and communications. In the absence of data about the actual movement of people between areas, attention is given to the physical provision for such movement in the form of shipping links, airline traffic, railways in Java, Madura, and in three separate areas of of Sumatra, road density, and the number of vehicles per head of population. Mass communications in the form of radio and television are considered again as components of this dimension, as are the use of telephones and telegrams and the flow of interregional mail. Migration offers a further measure of integration and so does the flow of interregional trade.

Finally, the economic dimension takes account of economic disparities between regions as indicated by the importance of agriculture and mining in the gross domestic product of each province, a consumer price index in the capital of each province, the percentage of the population living below a defined poverty line and the percentage living in deprivation. Other indices are examined also to enable a comparative judgment to be made about living standards: the use of electricity for lighting, the use of fuels other than wood or charcoal for cooking, and the possession of a sideboard. Taxation contributions to the central government, provincial government expenditures, and central government support for provincial development programs give indications of another kind.

Having surveyed regional inequalities according to the selected indices, province by province, Professor Drake proceeds to consolidate them. By a statistical procedure of correlation analysis which leaves this reviewer far behind, she analyzes separately the

\footnotetext{
${ }^{3}$ Karl W. Deutsch, Nationalism and Social Communication (Cambridge, Mass.: MIT Press, 1953).
} 
selected variables (over eighty of them) under the three major dimensions, determines the correlation of common factors from each dimension, and then draws the information together in an overall spatial analysis of each factor in order to produce a "more complete, composite picture of national integration in Indonesia" (p. 185). The method is impressively complex, though in places it runs into some fairly obvious difficulties to the existence of which she cheerfully admits. Examining the indices on a province by province basis may conceal significant intraprovincial comparisons and contrasts. This could be of particular importance in large, sparsely populated provinces where an average distribution of factors across the area is likely to be distorted by a concentration of relevant characteristics in the urban society of the provincial capital, or where a dense population across the province as a whole, as in the provinces of Java, affects comparison with other provinces. In conceding these points, Drake seeks to counteract them to some extent by standardizing her data to accommodate differences in area and population density. She also recognizes that the countermeasure has consequences of its own. It blurs, in particular, the obvious contrast between Java and the Outer Islands as it dilutes the concentration of urban characteristics by averaging them over Java's enormous number of people. For example Java has 71 percent of all of Indonesia's investment project approvals, but on a per capita basis it absorbs less foreign investment than Maluku, Irian Jaya, Sumatra, and Kalimantan. Java has over 80 percent of Indonesia's total manufacturing employment and has 73 large and medium manufacturing establishments per million of population, compared with 28 per million in Kalimantan (p. 178). But the regional disparities in per capita income are counterbalanced by the large number in Java below the defined poverty line. However, as Drake points out, "no index can adequately encompass both population and area differences at the same time" (p. 257).

She notices, too, the inescapable problems of data collection arising not only from doubts about the accuracy of statistics in Indonesia, but by the unavailability in some cases of the appropriate statistics. As already noticed, the movement of persons from province to province would have been a better index of interaction than figures of road networks and numbers of vehicles. And she draws attention to the difficulty of separating economic indicators from some of the others-ownership of radios and television, distribution of vehicles, numbers of telephone calls-or of distinguishing economic integration indicators from economic development indicators. Aceh, for example, dominates the economic growth and investment picture, but that does not necessarily demonstrate a greater degree of integration. It may merely show investment and development!

There are also problems of overlap between dimensions. Telephone links are considered as part of the socio-cultural and interaction dimensions, urbanization is examined under both economic and socio-cultural dimensions. Many of the correlations revealed by the figures would seem to cast doubt on the validity of treating them separately. Vehicle numbers, television ownership and exposure to the media in general, use of telephones, membership in organizations, access to such facilities as hospitals and medical and dental services, and what are described as modernizing features, would appear to be linked to urbanization and economic development and growth, which are treated as separate indices. These variables seem to be different in kind from, say, the distribution of religious differences or ethnic distribution, including the distribution of the Chinese minority. And the "dimensions" under which these variables are grouped are somewhat arbitrary. 
In spite of these difficulties there is clearly much in the analysis which bears on both the reality and the perceptions of national unity. Some of the findings are quite unsurprising. The exceptional character of Jakarta as the "national core" of Indonesia, the center of investment, finance, government and administration, and the focus for most communication and transportation links, is obvious enough without elaborate statistical demonstration. And the differences between Java and the Outer Islands emerge from some of the variables-road density, vehicle concentration, household modernization, higher use of electricity and kerosene, as though the Java/Outer Island dichotomy were thus empirically established. This leads Drake to a less obvious point, however. Having noted the common opposition of Java and the Outer Islands, and the associated view that it is Java which forms the Indonesian core, she points out that, on a per capita basis, the factors that one would expect to point to Java as the Indonesian center do not, in fact, distinguish Java from other provinces. On a per capita basis Java is underdeveloped as compared with, say, East Kalimantan or North and South Sumatra or Riau, and it does not display the dynamic characteristics associated with a national center. Apart from Jakarta, the provinces of Java are not even highly urbanized as compared with those other provinces. If it is only Jakarta and not Java that is the core, it can be argued on the basis of the evidence of other variables that Java (and Bali) are indeed not well integrated into the Indonesian nation. A higher proportion of the population speaks Indonesian in outlying areas in the Outer Islands-North and Central Sulawesi, Maluku, Sumatra, and East Kalimantan-than in Java. Yet language might be held to be one of the most important integrating features in any nation state. Literacy and educational levels are below the national average in most of Java. Less than 4 percent of the population of Java outside Jakarta has lived in another province.

After the consolidation of the evidence from the three dimensions some sort of pattern can be discerned. Drake classifies the provinces of Indonesia according to levels of integration based on per capita characteristics. For this purpose, certain characteristics emerge as being, apparently, more significant than others: in the socio-cultural dimension the urban- and media-related characteristics, literacy, education, and knowledge of Indonesian; in the interaction dimension, urban-related characteristics, road density, and sea transport; in the economic dimension, the indices of economic development and the modernizing aspects of changing life styles. On the basis of these factors, Indonesia's provinces fall into four groups.

West, Central and East Java, Yogyakarta, and Bali have similar scores which indicate that they are only partially integrated into the Indonesian nation state. The second group-East Kalimantan, North and South Sumatra, Riau, and North Sulawesi-are similar in displaying a comparatively high degree of urbanization and appear as the most economically developed and highly integrated provinces. East Kalimantan, indeed, throughout the whole study appears almost as exceptional as Jakarta in its high scores on what are seen in the analysis as the "major" indices. It is described as Indonesia's richest and most developed and developing province on a per capita basis. The third group comes near the average, or close below it, in most of the ratings and comprises South Kalimantan, Aceh, Jambi, South Sulawesi, West Sumatra, Central Sulawesi, Irian Jaya, Maluku, and West and Central Kalimantan. For this group, however, there is considerable variation in scores, with some provinces showing high ratings on certain indices and low on others. Finally five appear as the least integrated and least developed: Bengkulu, Lampung, Southeast Sulawesi, and West and East Nusatenggara. West and 
East Nusatenggara are characterized as the least developed and least integrated in the Republic. (Jakarta and East Timor are not included in the classification.)

Drake's overall conclusion is that "as might be expected" no simple spatial pattern of integration emerges from the data she has collected (p. 221). She mentions the geographical spread of those provinces that are described as more highly integrated. They are separated from each other; and less integrated provinces are interspersed amongst them and lie between them and Jakarta. Indonesia's pattern of integration is described, therefore, as uneven, and there is no uniform decreasing level of integration as one might expect to find as one moves outward from the capital. An unsurprising conclusion, perhaps. There remains, however, a concern about whether the indices do really indicate integration. For this reader, there is a certain ambiguity lying at the heart of the analysis. The conclusions about integration appear to emerge from the empirical data presented, but the selection of indices may, at the same time, reflect prior assumptions about what really constitutes integration. Urbanization, development, and growth, would appear, in the end, to be central to Drake's notion of the elements of integration. But might they not be part of a perception of unifying forces rather than a discovery about them-a definition of integration rather than an analysis of it? While development and growth, urbanization and modernization, might well be conditions of integration, it is equally possible that, if they are unevenly distributed throughout the archipelago, they could be disintegrative in their effect. Similarly, uneven distribution within a modernizing and urbanizing provincial society could create tensions and produce disruption rather than integration.

These possibilities are not ignored by Drake. They are noted but left suspended. In spite of the apparent implication that integration is a matter of ascertainable fact, her book does not, in the end, manage to capture the essence of what makes for the unity of a nation, and perhaps it did not really seek to do so. The question asked at the beginning remains unanswered. She does, however, point to many specific aspects which obviously bear in varying degrees upon that question and, in consequence, to aspects of the Indonesian problem which can be the subject of government policy. Her concluding chapters examine some of these and the actions taken to deal with them: the promotion of the national language, the extension of education, religious policy and the attempt to develop a national ideology, policies designed to improve communications and to reduce economic inequalities within and between Indonesia's diverse societies. She also raises the question of the desirable level of political control, and touches on the role of the Army and of Golkar. Throughout she remains aware of complexity and contradiction and her judgments are appropriately tentative.

This book is packed with fascinating and often unexpected detail. A close reading is a strenuous exercise, especially when one plunges into the details of its statistical analysis. But its method is provocative and stimulating and it represents a new approach to an old set of questions. 